\title{
ESTUDO DE CAPACIDADE DO CANAL DA GALHETA (PORTO DE PARANAGUÁ)
}

\author{
Autor: Eng. Civil. Samuel Sembalista Haurelhuk \\ Universidade Federal de Santa Catarina - LabTrans \\ samuelshaurelhuk@gmail.com \\ Coautor: Dr. Amir Mattar Valente \\ Universidade Federal de Santa Catarina \\ amir.labtrans@gmail.com
}

\begin{abstract}
Resumo
A importância do transporte hidroviário para a humanidade é incontestável tendo em vista que a maior parte do comércio exterior é realizado por via marítima. A globalização da economia mundial só intensifica a interdependência dos Estados Nacionais, a necessidade de cooperações, trocas de insumos, produtos, conhecimentos, e consequentemente a necessidade da utilização do modal marítimo. O bom andamento dessa organização econômica depende diretamente da condição em que se encontram os pontos inicial e final de todas essas trocas, os portos. Tendo esse cenário em vista, o presente trabalho aplica uma análise de capacidade em nível conceitual da configuração marítima do Porto de Paranaguá. A metodologia adotada é a proposta pela diretriz PIANC onde entram como variáveis dados físicos do local e características das embarcações que frequentam o porto, para ser possível definir as dimensões verticais e horizontais do Canal de Acesso, da Área de Fundeio e da Bacia de Evolução. Os resultados deste trabalho dão parecer quanto à capacidade da configuração marítima em questão e sugerem possíveis melhorias a serem aplicadas.

Palavras-Chaves: Portos; Capacidade; Canal de Acesso; Área de Fundeio; Bacia de Evolução.
\end{abstract}

\begin{abstract}
The ship transport carries out the majority of today's global trade making its importance to humankind undeniable. World's economy globalization only intensifies Nations' interdependency; need for cooperation; input, products and knowledge exchanges and; therefore, maritime industry development. Nowadays' economy organization success directly relies on the beginning and end of each trade, the ports. Facing the described reality, this work applies PIANC methodology to evaluate Paranagua port maritime configuration capacity. In the mentioned methodology, location's physical data together with vessel's normally navigating the area characteristics are variables that define Harbour Approach Channels, Anchorage Areas and Turning Basins vertical and horizontal dimensions. Results produced by this work enable comments related to the mentioned maritime configuration capacity and suggest improvements.
\end{abstract}

Keywords: $\quad$ Ports; Capacity; Approach Channel; Anchorages; Turning Basin. 


\section{INTRODUÇÃO}

A navegação, desde o início dos tempos, vem dando forma a organização humana. A expansão do conhecimento marítimo, materializado pela caravela, foi uma das principais razões para o sucesso Português na colonização da América [8]. Acredita-se que o primeiro Canal navegado tenha sido o Grande Canal Fluvial da China, construído no século VI. Leonardo da Vinci em 1515, por meio de um projeto de Canais e Eclusas, conseguiu resolver o problema das enchentes na região de Milão. Esses fatos dão embasamento histórico para a relevância da navegação e do setor portuário e marítimo como um todo na organização humana [13].

Estima-se que $80 \%$ do comércio exterior, com base em toneladas, seja transportado via marítima. Isso representou no ano de 2012 pouco mais de 9 bilhões de toneladas [19]. Atingiu-se, também no ano de 2012, a marca de 600 milhões de TEUs (Twenty-foot equivalent unit) movimentados. A não ser no ano de 2008 , devido a uma crise econômica, quando o comércio exterior teve queda, o prognóstico é de constante expansão.

O modal marítimo em si está revestido de vantagens inerentes a sua utilização, já que é, comparativamente às demais alternativas, limpo e ambientalmente favorável, além de muito eficiente energeticamente [11].

Ainda, de acordo com [18], temos em desenvolvimento a tendência da chegada de mega conteineiros e a consequente pressão sob a configuração marítima existente. Dentro desse contexto expansionista e globalizado, empreendedores buscam alternativas para tornar o trânsito de produtos entre as nações viável economicamente, tais como a expansão do Canal do Panamá e novas rotas marítimas no Ártico.

Ao analisarmos a balança comercial brasileira entre 2003 e 2012 é possível observar, segundo dados da ANTAQ [5] (Agência Nacional de Transportes Aquaviários), uma clara predominância do modal marítimo. Baseado no valor FOB (Free on Board) da mercadoria 84\% do transporte foi realizado por via marítima. A fatia chega a $98 \%$ se nos basearmos no volume em toneladas.

$\mathrm{O}$ desenvolvimento de um transporte seguro e eficiente é fundamental se levado em consideração os benefícios de tal realidade. O transporte corresponde em média a $60 \%$ dos custos logísticos [9] logo, qualquer redução obtida no setor é relevante. Ainda, aproximadamente 70 a $80 \%$ dos acidentes marítimos são causados por erro humano [14].

Segundo o Fórum Econômico Mundial em seu Relatório "Global Competitiveness 20132014" [18], competitividade é o conjunto de fatores, políticas e instituiç̃es que determinam o nível de produtividade de uma nação levando em consideração seu nível de desenvolvimento. O Relatório analisa 114 fatores em sua avaliação e, no quesito infraestrutura portuária, entre 148 nações pesquisadas, o Brasil encontra-se na $131^{\text {a }}$ posição, longe do ideal para um país com mais de $7.000 \mathrm{~km}$ de costa.

O critério básico para definir uma configuração marítima é a segurança de suas manobras e operações [12].

Ao verificarmos a relevância do setor portuário para uma nação, o contexto globalizado da economia, a tendência de expansão no comércio exterior, a predominância do modal marítimo nas transações internacionais aliado a suas inerentes vantagens, a necessidade de investimentos que a infraestrutura portuária nacional demanda, e a consequente pressão que sofre dentro do panorama apresentado, se justifica o estudo da segurança da Configuração Marítima de um dos mais importantes portos do país.

O objetivo será avaliar a capacidade de todas as áreas molhadas da Configuração Marítima do Porto de Paranaguá, ou seja, seu Canal de Acesso, sua Bacia de Evolução e sua Área de Fundeio. Dessa forma será possível classificá-la adequada ou inadequada para a navegação segura da embarcação tipo considerada na análise.

O trabalho inicia com o item 2 apresentando a metodologia de cálculo de capacidade para projeto de um canal, justificando a escolha feita e comentando sobre alternativas de simulação. No item 3 são designadas as características gerais, ambientais e das embarcações tipo consideradas no trabalho. No item 4, demonstram-se os cálculos realizados e classificação obtida em cada situação. Por fim, são apontadas as considerações finais e recomendações no item 5. 


\section{METODOLOGIA DE CÁLCULO DE CAPACIDADE PARA PROJETO DE UM CANAL}

\subsection{RAZÃO DA ESCOLHA}

Existem diversos referenciais utilizados pelo mundo tais como o Coastal Engineering Manual publicado pelo USACE (United States Army Corps of Engineers) e utilizada nos Estados Unidos da América, a ROM (Recomendaciones de Obras Marítimas) publicada pelo governo da Espanha e lá utilizada com força de norma, a publicada pela CCG (Canadian Coast Guard), utilizada no Canadá, a BSI (British Standard Institute) utilizadas no Reino Unido, a JIN (Japan Institute of Navigation) utilizada no Japão, cada uma com suas características próprias.

Dentre estes inúmeros referenciais existentes, o mais adequado é, no entender do próprio autor, o publicado pela PIANC (Permanent International Association of Navigation Congresses). Ele é, atualmente, o mais atualizado tendo em vista que foi publicado em 2014. Além disso, ele foi produzido por um grupo de trabalho internacional, em forte cooperação com a IAPH (International Association of Ports \& Harbours), a IMPA (International Maritime Pilots Association), e a IALA (International Association of Marine Aids to Navigation and Lighthouse Authorities), importantíssimos organismos do setor [12].

\subsection{PROCESSO DE PROJETO DE UM CANAL}

Segundo [12], canais são projetados num processo de dois passos: projeto conceitual e projeto detalhado.

O projeto conceitual é caracterizado por ser rápido e não prever a utilização de dados muito detalhados. São utilizados os processos empíricos para definição das características do Canal. É importante pois nessa fase é possível avaliar cenários inúmeros [12].

O projeto detalhado existe para refinar, aprimorar e validar o projeto conceitual adotado por meio de análises numéricas e físicas, com a utilização de simuladores. Essa fase demanda um aprofundamento maior dos dados e vasta experiência do projetista em analisar os resultados. $\mathrm{O}$ auxílio de profissionais da área da navegação, tais como práticos e mestres de rebocador, também se faz necessário [12].

Inicialmente, em nível de projeto conceitual, o primeiro passo é adotar uma ou mais embarcações tipo que poderão frequentar a referida configuração marítima, definindo assim alternativas a serem analisadas. Na sequência ao trabalho busca-se otimizar aspectos de navegação, segurança, meio ambiente, economia, dentre outros, reduzindo a amostra de alternativas que merecem ser analisadas em nível de projeto detalhado [12].

\subsubsection{Simulação}

Há dois tipos de modelo de simulação existentes atualmente, os quais possuem objetivos distintos: (a) simular a capacidade de um Canal por meio de manobra de atracação e sua viabilidade quanto a aspectos da segurança da navegação, ou (b) quantificar o tráfego máximo no Canal para determinar em conjunto com outras análises a capacidade de movimentação de cargas do sistema portuário [12].

O objetivo deste trabalho demanda uma análise dos simuladores de manobra.

\subsubsection{Simuladores de Manobra}

Há dois tipos de simuladores de manobra: Fast-time" e "Real-time". Ambos são compostos de software de simulação, modelos matemáticos de manobra de embarcações, banco de dados com as características geográficas e ferramentas de análise. A principal diferença entre eles é que no sistema "fast-time" um algoritmo navega a embarcação e posiciona automaticamente os rebocadores. No modelo "real-time" a navegação fica a cargo de um ser humano, geralmente o prático [12].

Os simuladores de manobra permitem uma dupla aplicação: (a) engenharia e pesquisa, (b) capacitação e treinamento. Vale destacar, no entanto, que demandam diferentes requisitos. Para 
pesquisa e engenharia o modelo deve reproduzir fielmente o comportamento físico na navegação de forma a constituir um extrapolador confiável e permitir análises da segurança de manobra de uma certa embarcação em dada condição ambiental. No caso da capacitação, deve reproduzi-lo qualitativamente, transmitindo as impressões, desafios, dificuldades que o operador teria inserido na situação ambiental definida em certa embarcação [17].

Os modelos matemáticos são mais confiáveis se baseados em dados obtidos em escala real. Podem ser também aferidos em tanques e tuneis de vento, modelos físicos em escala, e posteriormente calibrados por meio de parâmetros reais. Entretanto, é possível produzir resultados satisfatórios com a utilização de modelagem numérica e de modelos previamente utilizados de embarcações com características semelhantes [12].

As características geográficas dependem da coleta de dados topográficos, batimétricos e hidráulicos do local de análise e são muito importantes pois influem diretamente na resposta hidrodinâmica das embarcações [12].

A alternativa "fast-time" pode ser suficiente para manobras consideradas mais simples, sem muitas curvas, em trechos praticamente retilíneos. São necessárias várias manobras em cada situação considerada, com os parâmetros de resposta dos operadores variando dentro de certo intervalo, que permitam uma análise estatística dos dados e garantam validade significativa aos resultados. No entanto, por mais simples que seja o projeto de um Canal, a manobra de atracação não é trivial quando se está muito perto do cais, ou ainda quando se faz curvas na bacia de evolução. Logo, a dispensa de uma simulação "real-time" deve ser adotada com extrema cautela [12].

A alternativa "real-time" é a mais completa e próxima da realidade. O grau de sofisticação de um simulador "real-time" varia muito indo desde um monitor ou projetor e alguns controles apenas até simulação em $360^{\circ}$ e todos os controles disponíveis numa situação real ("Full-Mission Bridge"). Estes simuladores de passadiço são utilizados inclusive para treinamento de profissionais da navegação em formação. A simulação mais avançada é indicada para definição última das dimensões horizontais do Canal e posicionamento de auxílios à navegação. Sem dúvida, sua operação deve ser realizada por profissionais experientes do ramo e conhecedores do local, os práticos e mestres de rebocador, afim de se ter uma opinião realmente embasada e experiente. Somente a participação destes na simulação "real-time" confere a devida garantia de inserção dos fatores humanos e margens de erro [12].

\subsection{METODOLOGIA ADOTADA}

A metodologia aqui adotada é a Verificação Determinística, em termos conceituais devido à natureza dos dados disponíveis e a disponibilidade de recursos, proposta pela PIANC. Segundo ela, as dimensões do canal serão determinadas baseado em cálculos onde os dados físicos que temos em posse entrarão como variáveis. Os resultados permitirão analisar se é possível que a embarcação tipo estudada navegue de maneira segura pelo Canal. $\mathrm{O}$ autor não dispunha de recursos suficientes para custear uma simulação "fast-time" e portanto não a pode realizar.

\section{ESTUDO DE CASO - CONFIGURAÇÃO MARÍTIMA DO PORTO DE PARANAGUÁ}

\subsection{CARACTERÍSTICAS GERAIS}

O Canal da Galheta, que dá acesso ao Porto de Paranaguá e é objeto de estudo deste Trabalho, está situado no Estado do Paraná, no município de Paranaguá. O Porto de Paranaguá movimentou 41,9 milhões de toneladas em 2013, o que representa 4,5\% do total movimentado nos portos do país. A mencionada movimentação significa um incremento de 3,6\% em relação a 2012 [4]. A projeção de demanda para o ano de 2030 quantifica a movimentação total em quase 81 milhões de toneladas, um incremento de quase $100 \%$ sobre a movimentação atual [15].

A movimentação do Porto é principalmente de produtos agrícolas e itens correlatos, na modalidade de longo curso. Em ordem decrescente temos a soja (19,2\%), fertilizantes e adubos $(19,1 \%)$, farelo de soja $(13,1 \%)$, açúcar $(12,7 \%)$ e milho $(10,9 \%)$ [4]. Apesar dessa divisão de 
mercado, os investimentos que estão sendo realizados em portos do Arco Norte poderão tornar essa movimentação de produtos agrícolas por Paranaguá menos interessante aos produtores da região centro-oeste e norte. Estima-se que o percentual, baseado em toneladas para o ano de 2030, correspondente ao grão de soja passe a ser de $15 \%$. O contêiner, por sua vez, passará por uma expansão de $4,8 \%$ ao ano e será a carga mais representativa na divisão com $20 \%$ do total, totalizando 16 milhões de toneladas [15].

\subsubsection{Canal de Acesso}

Conforme há um aumento da movimentação em tonelagem de mercadorias, há uma tendência do aumento de atracações nos berços e de trânsitos de embarcações pelo Canal de Acesso ao Porto. No ano de 2012 foram realizadas 2.525 atracações no Porto e, estima-se que sejam realizadas 5.873 em 2030. A capacidade de tráfego do Canal da Galheta foi estimada em mais de 10.000 atracações por ano, o que dispensa a análise desse tipo no momento [15].

Se analisarmos as atracações em função do tipo de embarcação iremos encontrar uma predominância de carregadores de volume. Para a demanda projetada em 2030, considerando os 16 tipos de carga projetados no Plano Mestre de 2012, o Porto contará com 3.209 atracações de embarcações carregadores de volume e 2.664 atracações de embarcações carregadoras de peso. Apesar da predominância de conteineiros e PCCs no trânsito realizado pelo Canal da Galheta, não se pode menosprezar o trânsito de carregadores de peso [15]. O Canal da Galheta é subdividido pela Autoridade Portuária - APPA em três seções:

\subsubsection{Seção Alfa.}

Trata-se da parte mais externa do Canal com extensão de 8.635 metros. Ele corta o banco da Galheta, o qual possui profundidade natural de cerca de 5 metros e largura por toda a sua extensão de 200 metros. É a única seção não abrigada. Fica entre as boias luminosas $1 / 2$ e 9/10 e é praticamente retilínea, com apenas uma curvatura de raio muito elevado [15]. Possui profundidade de projeto de 15 metros [20].

A seção abriga o único trecho não considerado de dupla via ao longo de todo o Canal da Galheta, conforme pode ser observado na Norma de Tráfego Marítimo e Permanência nos Portos de Paranaguá e Antonina [2], em seu Capítulo 7 - PROCEDIMENTOS DE MANOBRAS, Item 7.1.4.

\subsubsection{Seções Bravo 1 e 2}

São as seções seguintes à Alfa. A seção Bravo 1 possui extensão de 6.075 metros e largura de 200 metros constantemente, com profundidade de projeto de 13,5 metros. Considera-se uma área semiabrigada. Fica entre as boias 9/10 e 15/16 e é completamente retilínea [15].

A seção Bravo 2 possui 14.471 metros de extensão e 150 metros de largura constantemente, com profundidade de projeto de 13,0 metros. Fica entre as boias $15 / 16$ e 30/31 e possui três curvas, todas com raio $>=$ a 2.000 metros. Fica totalmente inserido em área abrigada [15]. Considerando primeira curva como a mais a jusante, segunda como a intermediária e terceira como a mais a montante, entre si, a primeira e a segunda curva possuem distância de 3.519 metros. A segunda e a terceira curvas, por sua vez, 1.241 metros [20].

\subsubsection{Bacia de Evolução}

A totalidade da área situada em frente ao cais do Porto de Paranaguá consiste em sua bacia de evolução. Ela é dividida em três seções de largura que varia entre 450 e 550 metros [15]:

\subsubsection{Seções Charlie 1 e 2}

Situadas em frente ao cais público do Porto de Paranaguá. Possui profundidades que variam de 10,0 a 13,0 metros, com previsão de aprofundamento para 14,5 metros [15][20]. Possui dimensão longitudinal de aproximadamente 2.750 metros e transversal de 603 metros [20]. 


\subsubsection{Seção Charlie 3}

Situado em frente aos píeres da Fospar, Cattalini e Píer Público. Possui profundidade de 12,0 metros com projeto para atingir 14,0 metros [15][20]. Possui dimensão longitudinal de 2.200 metros e transversal de 343 metros [20].

\subsection{3. Área de Fundeio}

O Porto de Paranaguá possui 12 áreas destinadas à fundeio com utilização ordenada pela Norma de Tráfego Marítimo e Permanência nos Portos de Paranaguá e Antonina [2]. O fundeadouro 1 não será abordado pois atende o Porto de Antonina e o Terminal de Ponta do Félix, fugindo do escopo deste trabalho.

As profundidades de cada área, obtidas a partir de consulta às Cartas Náuticas 1821 e 1822, disponibilizadas pela CHM (Centro de Hidrografia da Marinha) e DHN (Diretoria de Hidrografia e Navegação) [6][7], à Planta da Porto enviada pelo TCP [20] e ao PDZPO [1] permitiram a compilação da tabela abaixo:

Tabela 1 - Dimensões Áreas de Fundeio.

\begin{tabular}{|c|c|c|c|}
\hline \multirow{2}{*}{ Área de Fundeio } & \multicolumn{2}{|c|}{ Dimensões $(\mathrm{m})$} & \multirow{2}{*}{ Profundidade $(\mathrm{m})$} \\
\cline { 2 - 3 } & Transversal & Longitudinal & \\
\hline 2 & 900 & 2.680 & $6 \mathrm{a} 14$ \\
\hline 3 & 310 & 830 & $7 \mathrm{a} 9$ \\
\hline 4 & 770 & 2.100 & $8 \mathrm{a} 12$ \\
\hline 5 & 550 & 1.800 & 11 a 14 \\
\hline 6 & 710 & 6.620 & 10 a 19 \\
\hline 7 & 710 & 1.590 & 10 a 11 \\
\hline 8 & 660 & 4.300 & 9 a 12 \\
\hline 9 & 730 & 3.170 & 9 a 12 \\
\hline 10 & 530 & 1.670 & 9 a 9 \\
\hline 11 & 760 & 4.570 & 12 a 17 \\
\hline 12 & - & - & \\
\hline
\end{tabular}

Fonte: Adaptado de [6]; [7]; [20]; [1].

\subsection{CARACTERÍSTICAS AMBIENTAIS}

\subsubsection{Clima}

Segundo a Secretaria da Agricultura e do Abastecimento do Estado do Paraná o regime climático do local baseado na classificação de Koppen, é do tipo Cfa. Essa classificação significa se tratar de clima subtropical; temperatura média no mês mais frio inferior a $18^{\circ} \mathrm{C}$ (mesotérmico) e temperatura média no mês mais quente acima de $22^{\circ} \mathrm{C}$, com verões quentes, geadas pouco frequentes e tendência de concentração das chuvas nos meses de verão, contudo sem estação seca definida.

\subsubsection{Pluviometria}

Conforme já sugere a classificação de Koppen, a estação mais chuvosa é o verão, e a menos chuvosa o inverno, não havendo períodos secos. As maiores precipitações diárias, em torno de $100 \mathrm{~mm}$ alcançando picos de $400 \mathrm{~mm}$, ocorrem no verão. A precipitação média mensal é de 200,5 $\mathrm{mm}[16]$.

Em relação a umidade do ar, Paranaguá apresenta médias mensais anuais em torno de 12.103 $\mathrm{mB}^{3}$. As maiores médias mensais ocorrem nos meses de junho, julho e agosto, já os mais baixos índices ocorrem nos meses de dezembro, janeiro e fevereiro [1].

\subsubsection{Ventos}

Os ventos na porção litorânea do estado do Paraná, o qual inclui Paranaguá, têm sua dinâmica definida, em sua ação sobre o ramo Atlântico da Massa Polar, pelo Anticiclone do Atlântico Sul e pelo Anticiclone Migratório Polar (BIGARELLA et al., 1978; apud, [1]). 
Segundo dados fornecidos pelo TCP (Terminal de Contêineres de Paranaguá) [20], obtidos através de modelagem numérica aplicada a dados previamente coletados para previsão meteorológica podemos afirmar que a direção predominante dos ventos fica entre nordeste e lésnordeste, com intensidade que não apresenta possibilidade nenhuma de ultrapassar $20 \mathrm{~m} / \mathrm{s}$. Apenas $22 \%$ dos ventos registrados chegaram a $8 \mathrm{~m} / \mathrm{s}$ e menos de $3 \%$ chegaram a $12 \mathrm{~m} / \mathrm{s}$.

\subsubsection{Ondas, Marés, Correntes, Densidade}

Levantamentos da altura da maré são realizados de forma contínua pela APPA por meio de dados obtidos em estações maregráficas automáticas operadas pela praticagem e instaladas na Galheta, no Porto de Paranaguá e no Terminal de Ponta do Félix. Por meio dessas estações, foi possível observar que a maré na região do Canal da Galheta é semidiurna com desigualdades diurnas [1].

A maré na região do Complexo Estuarino de Paranaguá (CEP) apresenta amplitude média de $2,2 \mathrm{~m}$ e caráter predominantemente semidiurno dentro do complexo, embora ocorram desigualdades e efeitos não lineares [1].

O regime de ondas produzido a partir da coleta de dados aferidos por meio de um AWAC (Acoustic Water and Current Profiler) encomendado pelo TPC, permite afirmar que a direção predominante das ondas fica entre nordeste e lés-nordeste, com altura que não ultrapassa em nenhuma ocasião 5 metros. A coleta de dados realizada pelo TCP corrobora a afirmativa da APPA constante em sua Norma de Tráfego Marítimo. Essa coleta foi realizada em 8 estações distribuídas ao longo da região de estudo e extrapoladas matematicamente às demais. Menos de $4 \%$ das ondas ultrapassa a altura de 2,5 metros.

Segundo [1] por meio da publicação do PDZPO, e do fornecimento de dados por parte do TCP [20], é possível afirmar que as correntes no Canal não ultrapassam 2,6 nós senão muito raramente.

\subsubsection{Condição Geotécnica do Solo e Assoreamento}

O fundo do Canal da Galheta é composto por $95 \%$ de grãos terrígenos sendo que areia fina é a fração granulométrica média [3].

Em dois fluxos principais, externo e interno, se divide o fluxo sedimentar que se desloca ao longo do litoral paranaense. Tanto no setor externo quanto no interno as taxas de sedimentação variaram em torno de $20.000 \mathrm{~m}^{3} / \mathrm{mês}$ [1].

\subsection{EMBARCAÇÃo TIPO}

A projeção de demanda por atracação no Porto de Paranaguá, constante no Plano Mestre do Porto publicado em 2013, sugere a análise dos dois principais tipos de embarcações quanto ao tipo de carga transportada. O tipo carregador de volume será representado por um porta contêiner e o tipo carregador de peso por um graneleiro. Dessa forma todas as manobras pelo canal estarão devidamente avaliadas.

A partir de contato feito com o TCP, constatou-se que a embarcação carregadora de volume com as maiores dimensões que navega atualmente o canal (CV1) possui as dimensões constantes na tabela a seguir. Existe a pretensão para que em breve comece a navegar o Canal da Galheta até atracação no TCP embarcação com as características da CV2. Ainda, devido à movimentação em toneladas ser predominantemente realizada por embarcações do tipo carregadoras de peso, e estas possuírem características que diferem significativamente em relação às carregadoras de volume, o graneleiro CP1 com as seguintes características foi escolhido por representar o de maiores dimensões a frequentar atualmente a configuração marítima. Por fim, um segundo graneleiro (CP2) será considerado, com dimensões maiores às máximas permitidas atualmente. As informações sobre embarcações carregadoras de peso foram obtidas a partir de contato com o prático Gustavo Martins $[10]$. 
Tabela 2 - Embarcações analisadas

\begin{tabular}{|c|c|c|c|c|c|c|}
\hline & $L_{\text {oa }}(\mathrm{m})$ & $L_{p p}(\mathrm{~m})$ & $B(\mathrm{~m})$ & $T(\mathrm{~m})$ & $D W T($ ton $)$ & TEUs \\
\hline CV1 & 332,2 & 318,0 & 48,2 & 12,5 & 123.843 & 10.595 \\
\hline CV2 & 368,0 & 352,0 & 51,0 & 14,5 & 152.300 & 13.806 \\
\hline CP1 & 225,0 & 215,0 & 32,2 & 13,1 & 61.400 & - \\
\hline CP2 & 245,0 & 233,0 & 43,0 & 14,3 & 82.000 & - \\
\hline
\end{tabular}

Fonte: Elaboração própria

\section{CÁlCULOS E RESULTADOS}

\subsection{DimenSÕES VERTICAIS}

\subsubsection{Dimensão Vertical do Canal de Acesso}

Afirmações obtidas por meio de contato com Gustavo Martins [10] sobre a manobra de atracação permitiram ao autor adotar faixa de velocidade da embarcação tipo inferior a 10 nós para o cálculo de embarcações graneleiras e entre 10 e 15 nós para porta contêineres.

As ondas estão no nível moderado já que durante a observação menos de $4 \%$ ultrapassaram $2 \mathrm{~m}$. A característica geotécnica do fundo do Canal é arenosa. Trata-se ainda de um Canal abrigado na seção Bravo 2, semiabrigado na seção Bravo 1 e externo na seção Alfa. Já que não encontramos estrutura alguma acima do Canal da Galheta, a análise do Calado Aéreo é dispensável.

Quanto às características (c) e (d) da tabela da PIANC. Inexiste especificação exata para a condição encontrada na seção Bravo 1 do Canal da Galheta, considerada semiabrigada. Para os valores a serem utilizados na multiplicação do calado das embarcações tipo avaliadas, a favor da segurança, foi utilizado o menor valor do intervalo proposto para a situação de Canal externo. Relacionados à condição geotécnica do fundo foi adotado um valor médio entre a situação abrigada e a externa para o valor de segurança adicional.

É necessário, ainda, adotar um valor para o fator $\left(F_{K}\right)$, que será 0,76 tanto para CV1 quanto CV2. Adotou-se o menor valor já que o projeto conceitual já é conservador por natureza e a adoção de um valor maior traria resultados excessivamente conservadores. $O$ ângulo de jogo $\left(\emptyset_{W R}\right)$ adotado será de $2^{\circ}$.

As profundidades recomendadas para cada seção do Canal da Galheta são:

Tabela 3 - Profundidade $\left(\boldsymbol{h}_{C D}\right)$ do Canal.
\begin{tabular}{|c|c|c|c|}
\hline$h_{C D}$ & \multicolumn{3}{|c|}{ Seção } \\
\cline { 2 - 4 }$(\mathrm{m})$ & Alfa & Bravo 1 & Bravo 2 \\
\hline CV1 & $17,39 \mathrm{~m}$ & $16,09 \mathrm{~m}$ & $15,04 \mathrm{~m}$ \\
\hline CV2 & $20,03 \mathrm{~m}$ & $18,53 \mathrm{~m}$ & $17,32 \mathrm{~m}$ \\
\hline CP1 & $17,53 \mathrm{~m}$ & $16,17 \mathrm{~m}$ & $14,81 \mathrm{~m}$ \\
\hline CP2 & $19,09 \mathrm{~m}$ & $17,61 \mathrm{~m}$ & $16,13 \mathrm{~m}$ \\
\hline
\end{tabular}

Fonte: Elaboração própria

Pode-se afirmar, com base nos resultados obtidos, comparados com a profundidade atual encontrada, que a seção Alfa, Bravo 1 e Bravo 2 encontram-se em não conformidade.

\subsubsection{Dimensão Vertical da Área de Fundeio}

Recomenda-se a profundidade de 1,1T na área de fundeio. Isso resulta nas seguintes profundidades, para cada embarcação tipo considerada:

Tabela 4 - Profundidade $\left(\boldsymbol{h}_{C D}\right)$ da Área de Fundeio.

\begin{tabular}{|c|c|c|c|c|}
\hline & CV1 & CV2 & CP1 & CP2 \\
\hline $\begin{array}{c}\text { Profundidade }\left(h_{C D}\right) \\
\mathrm{m}\end{array}$ & 13,75 & 15,95 & 14,41 & 15,73 \\
\hline
\end{tabular}

Fonte: Elaboração própria 
O que permite afirmar que algumas das áreas de fundeio estão em conformidade com as embarcações analisadas e outras não. A análise está sintetizada completamente na tabela a seguir:

\begin{tabular}{|c|c|c|c|c|}
\hline Área & CV1 & CV2 & CP1 & CP2 \\
\hline 2 & SIM & NÃO & NÃO & NÃO \\
\hline 3 & NÃO & NÃO & NÃO & NÃO \\
\hline 4 & $\mathrm{NÃO}$ & $\mathrm{NA} O$ & NÃO & $\mathrm{NA} O$ \\
\hline 5 & SIM & NÃO & NÃO & NÃO \\
\hline 6 & SIM & SIM & SIM & SIM \\
\hline 7 & NÃO & NÃO & NÃO & NÃO \\
\hline 8 & NÃO & NÃO & NÃO & NÃO \\
\hline 9 & NÃO & NÃO & NÃO & NÃO \\
\hline 10 & $\mathrm{NÃO}$ & 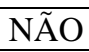 & $\mathrm{NÃO}$ & NÃO \\
\hline 11 & NÃO & NÃO & NÃO & NÃO \\
\hline 12 & SIM & SIM & SIM & SIM \\
\hline
\end{tabular}

Fonte: Elaboração própria

\subsubsection{Dimensão Vertical da Bacia de Evolução}

A três Bacias de Evolução analisadas, Charlie 1, 2 e 3 devem ter a mesma profundidade do Canal de Acesso que as conduz, portanto, a profundidade da seção Bravo 2 do Canal da Galheta.

Tabela 6 - Profundidade $\left(\boldsymbol{h}_{C D}\right)$ das Bacias de Evolução e Conformidade.

\begin{tabular}{|c|c|c|}
\hline $\begin{array}{c}\boldsymbol{h}_{\boldsymbol{C D}} \\
(\mathrm{m})\end{array}$ & Profundidade & Conformidade \\
\hline CV1 & 15,04 & NÃO \\
\hline CV2 & 17,32 & NÃO \\
\hline CP1 & 14,81 & NÃO \\
\hline CP2 & 16,13 & NÃO \\
\hline
\end{tabular}

Fonte: Elaboração própria

É possível afirmar que nenhuma das Bacias de Evolução está em conformidade com as profundidades mínimas calculadas.

\subsection{DIMENSÕES HORIZONTAIS}

\subsubsection{Dimensão Horizontal do Canal de Acesso}

\subsubsection{Largura do Canal de Acesso da Galheta}

Inicialmente determina-se o valor da via de manobra básica $\left(W_{B M}\right)$. A dimensão da via fica em função de sua boca $(B)$. As embarcações CV1 e CV2 foram consideradas de manobrabilidade moderada e as embarcações $\mathrm{CP} 1$ e $\mathrm{CP} 2$ de manobrabilidade pobre. Isso resulta nos seguintes valores para $W_{B M}$ :

Tabela 7 - Via de Manobra Básica do Canal da Galheta.

\begin{tabular}{|c|c|c|c|}
\hline$W_{B M}$ & \multicolumn{3}{|c|}{ Seção } \\
\cline { 2 - 4 }$(\mathrm{m})$ & Alfa & Bravo 1 & Bravo 2 \\
\hline CV1 & 72,3 & 72,3 & 72,3 \\
\hline CV2 & 76,5 & 76,5 & 76,5 \\
\hline CP1 & 57,96 & 57,96 & 57,96 \\
\hline CP2 & 77,4 & 77,4 & 77,4 \\
\hline
\end{tabular}

Fonte: Elaboração própria 
Seguindo com os cálculos, em relação à velocidade da embarcação $\left(V_{s}\right)$, foi aplicado o intervalo de 8 nós a 12 nós para as 4 embarcações analisadas e para todas as características aplicáveis, em virtude do relato prestado pelo prático Gustavo Martins [10].

Em relação aos ventos de través considerou-se adequado adotar a categoria suave. As correntes de través predominantes foram encaixadas na categoria baixa. Adotou-se o valor médio entre a situação externa e interna para a seção Bravo 1. As correntes longitudinais predominantes foram encaixadas na categoria moderado.

Quanto à altura das ondas na proa e popa, interpretou-se estar no nível moderado. Para a seção Bravo 1 foi considerado um valor de 0,2 bocas $(B)$ em vista seu caráter transitório entre interno e externo.

Os auxílios à navegação foram considerados bons já que existe DGPS, linhas de guia iluminadas, boias iluminadas e casadas com refletores de radar no Canal. Eles não puderam ser considerados excelentes uma vez que não há VTMS.

A relação profundidade calado $\left(h / T_{T}\right)$ no Canal é menor que 1,5 para todas as embarcações analisadas e o fundo foi encaixado na categoria liso e macio. As relações menores que 1,0 sugerem um toque no fundo. Elas só foram encontradas felizmente para embarcações que ainda não navegam o Canal. Ainda, as profundidades analisadas não levam em consideração a amplitude da maré, que pode gerar janelas de navegação possíveis. Para a região Bravo 1 foi considerado um fator multiplicador de 0,3 bocas, valor médio entre a situação interna e externa.

Nenhuma das embarcações analisadas carrega cargas de alta periculosidade, o que dispensou a análise do último item.

Adiante, foi avaliada a distância às margens vermelha $\left(W_{B R}\right)$ e verde $\left(W_{B G}\right)$. Os bordos do Canal foram considerados medianamente inclinados dado a razão 1:4.

Nas seções Bravo 1 e 2, de dupla via, é importante considerar o termo distância de cruzamento $\left(W_{P}\right)$. Para a seção semiabrigada Bravo 1 adotou-se o fator multiplicador 1,5, valor médio entre o proposto para a situação interna e externa.

A dimensão adicional devido à amplitude de maré muito elevada não se aplica às condições do Canal da Galheta.

As larguras resultantes para as seções do Canal da Galheta estão contidas na tabela a seguir:

Tabela 8 - Larguras Resultantes para o Canal da Galheta.

\begin{tabular}{|c|c|c|c|}
\hline \multirow{2}{*}{$\begin{array}{c}W \\
(\mathrm{~m})\end{array}$} & Alfa & Bravo 1 & Bravo 2 \\
\cline { 2 - 4 } CV1 & 171,11 & 349,46 & 351,86 \\
CV2 & 181,05 & 390,16 & 372,32 \\
CP1 & 123,97 & 262,44 & 254,38 \\
CP2 & 165,55 & 354,76 & 339,7 \\
\hline
\end{tabular}

Fonte: Elaboração própria

Dado os resultados, é possível afirmar que a seção Alfa encontra-se adequada para o trânsito das embarcações avaliadas e as seções Bravo 1 e Bravo 2 encontram-se inadequadas.

\subsubsection{Curvas e Alinhamento do Canal de Acesso}

As três curvas existentes na seção Bravo 2 estão voltadas para a mesma direção e, portanto, demandam distância entre si de ao menos 3 comprimentos totais $\left(L_{o a}\right)$ da embarcação considerada. A tabela a seguir fornece os valores resultantes. 
Tabela 9 - Comprimento Mínimo da Seção Reta entre Curvas do Canal da Galheta.

\begin{tabular}{|c|c|}
\hline & $\begin{array}{c}\text { Comprimento mínimo } \\
\text { da seção reta }(\mathrm{m})\end{array}$ \\
\hline CV1 & 996,6 \\
\hline CV2 & 1104,0 \\
\hline CP1 & 675,0 \\
\hline CP2 & 735,0 \\
\hline
\end{tabular}

Fonte: Elaboração própria

As duas seções retas que distanciam as três curvas existentes na seção Bravo 2 estão adequadas.

$\mathrm{O}$ raio de curva mínimo adequado às embarcações CV1 e CV2 é de 7 comprimentos totais $\left(L_{\text {oa }}\right)$ e às embarcações $\mathrm{CP} 1$ e CP2 de 6 comprimentos totais $\left(L_{\text {oa }}\right)$. Portanto:

Tabela 10 - Raio Mínimo de Curvas do Canal da Galheta.

\begin{tabular}{|c|c|}
\hline & $\begin{array}{c}\text { Raio mínimo de curvas } \\
(\mathrm{m})\end{array}$ \\
\hline CV1 & 2325,4 \\
\hline CV2 & 2576,0 \\
\hline CP1 & 1350,0 \\
\hline CP2 & 1470,0 \\
\hline
\end{tabular}

Fonte: Elaboração própria

A fonte pesquisada não traz o raio exato das três curvas, somente que são maiores de 2.000 metros. Pode-se afirmar inequivocamente, portanto, que se encontram adequadas às embarcações $\mathrm{CP} 1$ e CP2.

\subsubsection{Dimensão Horizontal da Área de Fundeio}

A dimensão horizontal da Área de Fundeio se dá pela adição de seis dimensões. O primeiro termo da soma está em função da embarcação tipo, portanto, consulta inequívoca.

Todos as áreas de fundeio do Porto de Paranaguá, à exceção da número 12, foram consideradas de boa proteção. Como o tempo de estada para atracar é de caráter operacional e varia muito, adotou-se o valor médio do intervalo proposto na bibliografia, 3,5 profundidades em maré alta. $\mathrm{O}$ fundeadouro 12 é externo e foi considerado de piores condições. Adotou-se para ele o valor médio do intervalo proposto, de 6 profundidades na maré alta.

A margem de segurança adicional adotada foi de $25 \%$ do comprimento total.

As condições geotécnicas do solo foram consideradas boas para ancoragem sendo possível encaixar essa parcela na condição $0 \mathrm{~m}$.

A última parcela fica para todas as embarcações testadas em $10 \%$ de seu comprimento total.

Os resultados obtidos para a característica da embarcação $\left(L_{C}\right)$ disponíveis na Tabela a seguir adotaram o valor mais profundo do intervalo apresentado na tabela "Dimensões Áreas de Fundeio" a favor da segurança. Também estão disponíveis as dimensões horizontais resultantes por embarcação e por Área de Fundeio. 
Tabela 11 - Característica da Embarcação $\left(\boldsymbol{L}_{\boldsymbol{C}}\right)$ para Área de Fundeio e Dimensão Horizontal Resultante.

\begin{tabular}{|c|c|c|c|c|c|}
\hline \multirow{2}{*}{ AF } & \multirow{2}{*}{$L_{C}(\mathrm{~m})$} & \multicolumn{5}{|c|}{$\mathrm{DH}(\mathrm{m})$} \\
\hline & & $\mathrm{CV} 1$ & $\mathrm{CV} 2$ & $\mathrm{CP} 1$ & $\mathrm{CP} 2$ \\
\hline 2 & 49,0 & 497,47 & 545,80 & 352,75 & 382,75 \\
\hline 3 & 31,5 & 479,97 & 528,30 & 335,25 & 365,25 \\
\hline 4 & 42,0 & 490,47 & 538,80 & 345,75 & 375,75 \\
\hline 5 & 49,0 & 497,47 & 545,80 & 352,75 & 385,75 \\
\hline 6 & 66,5 & 514,97 & 563,30 & 370,25 & 400,25 \\
\hline 7 & 38,5 & 486,97 & 535,30 & 342,25 & 372,25 \\
\hline 8 & 42,0 & 490,47 & 538,80 & 345,75 & 375,75 \\
\hline 9 & 42,0 & 490,47 & 538,80 & 345,75 & 375,75 \\
\hline 10 & 31,5 & 479,97 & 528,30 & 335,25 & 365,25 \\
\hline 11 & 45,5 & 493,97 & 542,30 & 349,25 & 379,25 \\
\hline 12 & 102 & 550,47 & 598,80 & 405,75 & 435,75 \\
\hline
\end{tabular}

Fonte: Elaboração própria

Comparando os dados obtidos e apresentados na Tabela 11 com as dimensões atuais das Áreas de Fundeio disponíveis na Tabela 5 é possível afirmar que a conformidade é parcial, conforme sintetiza a tabela a seguir.

Tabela 12 - Conformidade Áreas de Fundeio.

\begin{tabular}{|c|c|c|}
\hline \multirow{2}{*}{$\begin{array}{l}\text { Área de } \\
\text { Fundeio }\end{array}$} & \multicolumn{2}{|c|}{ Conformidade } \\
\hline & Transversal & Longitudinal \\
\hline 2 & $\mathrm{CP} 1-\mathrm{CP} 2$ & $\mathrm{CV} 1-\mathrm{CV} 2-\mathrm{CP} 1-\mathrm{CP} 2$ \\
\hline 3 & NÃO & $\mathrm{NÃO}$ \\
\hline 4 & $\mathrm{CP} 1-\mathrm{CP} 2$ & $\mathrm{CV} 1-\mathrm{CV} 2-\mathrm{CP} 1-\mathrm{CP} 2$ \\
\hline 5 & NÃO & $\mathrm{CV} 1-\mathrm{CV} 2-\mathrm{CP} 1-\mathrm{CP} 2$ \\
\hline 6 & NÃO & $\mathrm{CV} 1-\mathrm{CV} 2-\mathrm{CP} 1-\mathrm{CP} 2$ \\
\hline 7 & CP1 & $\mathrm{CV} 1-\mathrm{CV} 2-\mathrm{CP} 1-\mathrm{CP} 2$ \\
\hline 8 & $\mathrm{NÃO}$ & $\mathrm{CV} 1-\mathrm{CV} 2-\mathrm{CP} 1-\mathrm{CP} 2$ \\
\hline 9 & CP1 & $\mathrm{CV} 1-\mathrm{CV} 2-\mathrm{CP} 1-\mathrm{CP} 2$ \\
\hline 10 & $\mathrm{NÃO}$ & $\mathrm{CV} 1-\mathrm{CV} 2-\mathrm{CP} 1-\mathrm{CP} 2$ \\
\hline 11 & $\mathrm{CP} 1-\mathrm{CP} 2$ & $\mathrm{CV} 1-\mathrm{CV} 2-\mathrm{CP} 1-\mathrm{CP} 2$ \\
\hline 12 & 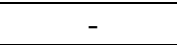 & - \\
\hline
\end{tabular}

Fonte: Elaboração própria

\subsubsection{Dimensão Horizontal da Bacia de Evolução}

O diâmetro nominal mínimo das Bacias de Evolução Charlie 1, 2 e 3 pode ser considerado $2 L_{\text {oa }}$ já que não possuem nenhuma característica que demande cuidado especial e se trata de Porto dotado de rebocadores para auxílio nas manobras.

Portanto:

Tabela 13 - Diâmetro Nominal das Bacias de Evolução.

\begin{tabular}{|c|c|}
\hline Embarcação & $\begin{array}{c}\text { Diâmetro Nominal Mínimo das } \\
\text { Bacias Charlie 1, 2 e 3 (m) }\end{array}$ \\
\hline CV1 & 664,4 \\
\hline CV2 & 736,0 \\
\hline CP1 & 450,0 \\
\hline CP2 & 490,0 \\
\hline
\end{tabular}

Fonte: Elaboração própria

O que confere um caráter de conformidade parcial. As três Bacias estão adequadas na dimensão longitudinal, com larga folga. Já no quesito transversal, foi identificada desconformidade. As Bacias Charlie 1 e 2 possibilitam a evolução das embarcações CP1 e CP2 e não possibilitam a 
evolução das embarcações CVI e CV2. A Bacia Charlie 3 não possibilita a evolução de nenhuma das embarcações analisadas.

\section{CONCLUSÃO}

\subsection{CONSIDERAÇÕES FINAIS}

Os resultados obtidos durante o trabalho realizado permitem tecer alguns comentários referentes ao tema bem como sugerir futuras investigações.

Baseado em relatos de profissionais da área marítima e portuária, os quais o autor teve intenso contato durante o desenvolvimento do trabalho, bem como em pesquisas acadêmicas prévias vivenciadas durante sua trajetória acadêmica de pesquisa, se pode constatar que a grande carência de investimentos que acometeu o setor durante muitos anos repercute atualmente. Levantamentos simples de dados ambientais são por vezes inexistentes em muitos portos do país e a imprescindibilidade destes para o desenvolvimento de estudos impede consequentemente a adoção de configurações marítimas mais seguras e eficientes. Além de dados, faltam especialistas e centros de pesquisa capazes de processá-los.

A realidade de Paranaguá em nível conceitual de projeto se mostrou pouquíssimas vezes adequada até mesmo para a situação atual e principalmente não conforme com as pretensões futuras dos operadores do local. Deve-se considerar, certamente, que uma análise em nível conceitual é conservadora por natureza e a continuidade do estudo certamente credenciaria as manobras realizadas para as embarcações CV1 e CP1, uma vez que elas já ocorrem e não há registro de incidentes até o momento. Contudo, o presente estudo fica como indicativo claro da perícia dos envolvidos nas manobras no Canal da Galheta, práticos e mestres de rebocador, já que os valores excedem significativamente o recomendado pela diretriz utilizada e mais respeitada atualmente no mundo.

\subsection{RECOMENDAÇÕES}

O autor corrobora as recomendações da diretriz utilizada para a realização deste trabalho, diretriz PIANC, com as seguintes considerações.

A escolha das embarcações tipo neste trabalho se deu a partir de consultas feitas a profissionais da área portuária, mais especificamente do Terminal de Contêineres de Paranaguá, e marítima, prático Gustavo Martins. No entanto, uma análise completa da situação econômica dotada de projeção de demanda aquaviária, consulta a outros operadores poderia sugerir a necessidade de analisar um número maior de possibilidades, incluindo casos mais específicos. $\mathrm{O}$ aprofundamento do processo determinístico é, portanto, recomendada, já que é exatamente o que se espera da fase de projeto conceitual.

$\mathrm{Na}$ sequência, utilizar dos novos cálculos determinísticos bem como os realizados por este trabalho e realizar simulações "fast-time", de modo a reduzir o número de possibilidades antes de prosseguir para o nível detalhado de projeto.

Por fim, passar a fase detalhada de projeto, a qual é dotada de análises completas de cada aspecto interveniente na utilização de dada configuração marítima. Dar sequência a esse detalhamento com simulações "real-time" de forma a agregar experiência prática ao trabalho de mesa de projeto. Dessa forma, será atingido não só o principal objetivo de uma configuração marítima, que é a navegação segura das embarcações, como também a melhor alternativa do ponto de vista econômico, comercial, ambiental, social e humano.

Baseado nos resultados até aqui obtidos, ficariam recomendados o aprofundamento e alargamento do Canal de Acesso, ampliação da dimensão transversal das Bacias de Evolução e Área de Fundeio, bem como suas profundidades. Apesar do grande número de intervenções propostas, cabem colocações peculiares.

No caso específico da Área de Fundeio, o aumento da profundidade poderia ser discutido em termos operacionais já que uma atracação direta pode ocorrer, caso haja o devido planejamento. Frente ao parâmetro horizontal, a checagem pressupôs embarcações que largaram somente uma 
âncora a frente e, portanto, podem girar ao seu redor, o que demanda uma multiplicação da distância obtida por dois. As áreas da configuração marítima estudada possuem, em sua grande maioria, caráter retangular e dimensões generosas no parâmetro longitudinal. Caso fosse necessária uma economia de recursos, poderia se buscar uma alternativa operacional para resolver a não conformidade, tal como a utilização de uma âncora de proa e outra de popa.

O píer 217, o qual se encontra mais a jusante do Porto e próximo ao Canal do Surdinho, poderia ter manobras que a ele se destinam facilitadas sobremaneira se executada a derrocagem das Pedras do Surdinho e Palangana. Além dessa obra resultar numa maior margem de segurança às manobras, ela traria inclusive um aumento da capacidade do próprio Canal de Acesso, ficando como uma ação recomendada. 


\section{REFERÊNCIAS BIBLIOGRÁFICAS}

[1] ADMINISTRAÇÃO DOS PORTOS DE PARANAGUÁ E ANTONINA - APPA. Plano de Desenvolvimento e Zoneamento - PDZPO do Porto de Paranaguá: Relatório Final. Florianópolis, jul. de 2012.

[2] ADMINISTRAÇÃO DOS PORTOS DE PARANAGUÁ E ANTONINA - APPA. Norma de Tráfego Marítimo e Permanência nos Portos de Paranaguá e Antonina. Paranaguá, 2012.

[3] ARAÚJO, Alfredo Duarte de. DINÂMICA SEDIMENTAR E EVOLUÇÃO PALEOGEOGRÁFICA DO SACO DO LIMOEIRO NA ILHA DO MEL, E SUA RELAÇÃO COM O CANAL DE ACESSO AO PORTO DE PARANAGUÁ. 2001. 73 f. Dissertação (Mestrado) - Curso de Geologia, Universidade Federal do Paraná, Curitiba, 2001. Disponível em: <http://ojs.c3sl.ufpr.br/ojs/index.php/geociencias/article/viewFile/4187/3384>. Acesso em: 21 out. 2014.

[4] BRASIL. Antaq. Agência Nacional de Transportes Aquaviários. Anuário Estatístico. Brasília: Antaq, 2013. Disponível em: < http://www.antaq.gov.br/portal/Anuarios/Anuario2013/index.htm>. Acesso em: 10 set. 2014.

[5] BRASIL. Antaq. Agência Nacional de Transportes Aquaviários. Boletim Anual de Movimentação de Cargas: Análise da Movimentação de Cargas nos Portos Organizados e Terminais de Uso Privativo. Brasília: Antaq, 2014. Disponível em: <http://www.antaq.gov.br/portal/PublicacoesTecnicas.asp>. Acesso em: 10 set. 2014.

[6] BRASIL. Centro de Hidrografia da Marinha. Diretoria de Hidrografia da Marinha. Carta Nautica 1821: Barra de Paranaguá. Niteroi: Centro de Hidrografia da Marinha, 2014. Disponível em: <http://www.mar.mil.br/dhn/chm/box-cartas-raster/raster_disponiveis.html>. Acesso em: 15 set. 2014.

[7] BRASIL. Centro de Hidrografia da Marinha. Diretoria de Hidrografia da Marinha. Carta Nautica 1822: Portos de Paranaguá e Antonina. Niteroi: Centro de Hidrografia da Marinha, 2014. Disponível em: <http://www.mar.mil.br/dhn/chm/box-cartasraster/raster_disponiveis.html>.Acesso em: 15 set. 2014.

[8] FAUSTO, Boris. História do Brasil. 2. ed. São Paulo: Editora da Universidade de São Paulo, 1994.

[9] FLEURY, Paulo Fernando et al. Logística Empresarial: a perspectiva brasileira. São Paulo: Atlas, 2000.

[10] MARTINS, Gustavo. Área de Fundeio - Velocidade de Atracação. [mensagem pessoal] Mensagem recebida por:<samshflp@gmail.com>. em: 18 out. 2014. 
[11] INTERNATIONAL MARITIME ORGANIZATION. The Origins of IMO. London, 2012. Disponível em: <http://www.imo.org/blast/mainframe.asp?topic_id=1726>. Acesso em: 05 de set. 2014.

[12] PERMANENT INTERNATIONAL ASSOCIATION OF NAVIGATION CONGRESSES. Harbour Approach Channels - Design Guidelines. Bruxelles, 2014. Disponível em: < http://www.pianc.org/downloads/publications>. Acesso em: 08 de ago. 2014.

[13] SANTOS, Sílvio dos. Aspectos da Navegação Interior. Florianópolis: Labtrans/UFSC, 2014. 413p.

[14] SCHENK, Siegberto. Gestão e Análise de Risco: São Paulo: Praticagem Zp-14, 2014. 99 slides, color.

[15] SECRETARIA DE PORTOS DA PRESIDÊNCIA DA REPÚBLICA - SEP/PR. Plano Mestre - Porto de Paranaguá. Florianópolis, ago. 2013.

[16] SECRETARIA DE PORTOS DA PRESIDÊNCIA DA REPÚBLICA - SEP/PR. Instituto Nacional de Pesquisas Hidroviárias. Estudo de Sedimentação no Canal de Acesso ao Porto de Paranaguá. Rio de Janeiro, 2014. 44p. Disponível em: < http://www.portosdobrasil.gov.br>. Acesso em: 15 de set. 2014.

[17] TANNURI, Eduardo A. Modelagem matemática de manobras e validação de simuladores. São Paulo: TPN-USP, 2014. 43 slides, color.

[18] UNITED NATIONS. United Nations Conference on Trade and Development Review of Maritime Transport. New York and Geneva: United Nations Publication, 2013. Disponível em: < http://unctad.org/en/publicationslibrary/rmt2013_en.pdf>. Acesso em: 25 de ago. 2014.

[19] WORLD ECONOMIC FORUM. The Global Competitiveness Report 2013 - 2014. Geneva: World Economic Forum, 2013. Disponível em: <www.weforum.org/gcr>. Acesso em: 10 de out. 2014.

[20] TERMINAL DE CONTÊINERES DE PARANAGUÁ. Dados. [mensagem pessoal] Mensagem recebida por: <samshflp@gmail.com>.em: 18 ago. 2014. 